determining the tests for colour-vision in the mercantile marine, and these and other difficulties will have to be met in fixing the visual standards for railway service. The problem is not one for the ophthalmic surgeon alone, but there are certain points on which his aid is essential, and we know that it will be welcomed by the managing bodies of the great railway lines. Apart from the question of colour-vision, there is the need for settling what the minimum of form-sense is that can fit a man for driving an engine, and what kind of test is most suitable. To advise on this requires the combination of the oculist and the engine driver. In daytime there are various influences which affect the visibility of a signal, e.g., the nature of the background against which it shows, or the amount of shadow thrown by its surroundings at different times. Signals cannot always be placed so as to show up against a clear north sky. At night the luminosity and the colour of the signal become of an importance equal to the size. So far as we know, there has been no scientific eftort made to standardize any one of the factors nor to arrive at the minimum of form-sense which will enable a man to serve as an efficient and safe driver.

A further problem which will require very tactful handling is that of periodical re-examination. No ophthalmic surgeon will deny the need of this, both as regards form and colour; and yet even in the mercantile marine once a man has passed for his first colour-vision test he is subject to no further examination, although he is possibly more liable than men in other jobs to tobacco poisoning. We think that any ophthalmic surgeon who has an opportunity of considering the various problems involved, will be doing a service to the country if he can formulate some scheme as the basis of discussion.

\title{
A Commission of Enquiry on Cinemas
}

A Commission appointed by the National Council of Public Morals for Great and Greater Britain at the instance of certain cinematograph trade associations, has issued its Reportas an imposing volume containing nearly 300 pages.* As regards the well-known cinematograph eye-strain, the Commission recommended "a new copy of each film at every performance," but this was weakened by the addition of the words "or, at least, at frequent intervals." It was also suggested that children should sit at a distance from the screen not less than one and a half times its height, and that the front seats should be removed to at least twenty feet from the screen. The adequate illumination of the picture houses whilst the films are being shown, and other entertainment, as music and songs, were

*Williams and Norgate, London,1917, price 10s. 6d. net. 
advocated to relieve the constant strain on the eyes. Further, that children should not attend too frequently or stay too late. Another recommendation was that power should be given to close the cinema to children in times of epidemics.

As regards the lighting of cinema theatres, the Commission thought the recommendation made by the Secretary of the Illuminating Engineering Society to be reasonable, namely, that while the display was in progress it should be one-tenth of a foot-candle.

\section{Ophthalmia Neonatorum}

The News Letter is the title of a periodical published five times a year by the National Committee for the Prevention of Blindness, 130, East 22nd Street, New York City, N.Y. The number for October, 1917 (which has recently reached us), contains a table giving statistics of ophthalmia neonatorum during 1916-1917 in thirty State schools for the blind throughout the United States. Briefly, among the 2,961 pupils in thirty State schools, 742, or 25 per cent., had been blinded by the disease; while as regards 558 new admissions, 109 , or 19.5 per cent., were in similar case. Closer scrutiny of the figures shows curious differences in the schools belonging to different States. For example, in the Florida State school, those blinded by ophthalmia reach $51^{\circ} 1$ per cent. of the total pupils, and in the New Mexico institution, 44.8 per cent. ; whereas in the Montana, Virginia, and Nebraska schools, the figures are $7 \cdot 6$ per cent., $7 \cdot 3$ per cent., and $1 \cdot 7$ per cent. respectively. By means of another table it is shown that the proportion of pupils newly admitted to schools for the blind during the last ten years, blinded by ophthalmia neonatorum, has ranged from 26.5 per cent. $(1907-8)$ to $15^{\circ} 1$ per cent. (1914-15). With regard to the pupils in classes in the public school systems of six American cities, of 375 pupils, 54 , or 14.4 per cent., were blinded by ophthalmia neonatorum; while of 89 admissions to those classes, 10, or 11.2 per cent., were rendered necessary by that disease.

\section{"Collosol" Cocain}

Some few months ago (July, 1917, p. 440) we drew attention in these columns to a new product, "collosol" cocain, made by the Crookes Laboratories, London, and to its interesting possibilities in eye work. The other side of the question is now presented in the Lancet of December 1, 1917, by Messrs. G. Barger and H. H. Dale and Miss Florence M. Durham. Briefly, in the first communication it was claimed, apparently upon good evidence, that while retaining its anaesthetic action, "collosol" cocain has lost its general toxicity. 